\title{
The Diagnosis and Treatment of Insomnia
}

\author{
Michał Skalski \\ Department of Psychiatry Medical University of Warsaw, \\ Sleep Disorders Outpatients Clinic \\ Poland
}

\section{Introduction}

Insomnia is the most common sleep disorder. It is also, together with pain and fatigue, the most common ailment among all of us. Insomnia can be a standalone diagnostic category, but just like fever or pain, can be a symptom of another disease, either somatic or mental. Though insomnia is a prevalent condition in our society, both doctors and patients are lacking in the knowledge about it. There are also no generally accepted standards of treatment, especially the pharmacological.

Sleepless nights happen to everyone. Many scientists and most of the society think of insomnia as a natural reaction of the organism to tension or noise. The popular opinion is right. It is natural - this condition is called short-term insomnia or adjustment insomnia (according to ICSD - International Classification of Sleep Disorders; AASM, 2005) - when the sleeplessness is related to stress and anxiety. But as the researches show - the short-term insomnia can easily transform into a chronic condition. Numerous epidemiological studies have discovered that about $30 \%$ of the world's population, including more than $50 \%$ of people older than 60 and almost $20 \%$ of those younger declare sleep disorders. One third of these cases can be qualified as chronic insomnia (Ohayan, 1997; Szelenberger \& Skalski 1999).

There are many explanations of such a distinctive increase in number of complaints of insomnia, as the natural adjustment to the changing world, lifestyle, circadian rhythm disorders or as a syndrome of worsening physical and mental state of society. Although some facts are hard to disagree with, it is worth to mention that some researchers say it does not make much sense to talk about insomnia in the categories we got used to. They believe sleep is just one of our basic needs - we sleep to deal with fatigue as we eat to deal with hunger. They compare insomnia to obesity - both result from an inappropriate lifestyle. Eating too much results in obesity. Being lazy and having exaggerated expectations of the sleep result in insomnia. Authors of these ideas underpin their concepts with researches of animals' sleep where the animals living in natural conditions having to fight for their survival sleep distinctively shorter than the ones living in safety of a laboratory. In conclusion, we complain of insomnia because we are wealthy, safe and have too much spare time we want to fill with sleeping (Anderson \& Horne, 2008). 
Can the modern science help us to resolve these dilemmas? In the following book chapter we will try to resolve problems associated with diagnosing and treating insomnia and will try to present practical solutions for sleeplessness.

\section{Insomnia - definitions, diagnostic criteria}

What is insomnia? A basic definition of insomnia can be easily derived from what we have describe before. Insomnia is a subjective feeling of not getting enough sleep in terms of its length and quality together with its consequences, such as being unproductive and in bad mood during daytime.

Types of insomnia:

Insomnia is generally divided into primary and secondary insomnia. Primary insomnia appears for no apparent reason, secondary is related to another diseases. Another popular criteria are how long insomnia persists. Transient insomnia lasts for a few days to a week, acute insomnia (up to one month) and chronic insomnia (more than one month) (NIMH, 1984).

\subsection{Criteria of diagnosing insomnia}

The following are the most common and accepted definitions and diagnostic criteria of insomnia according to ICD-10, DSM-IV-TR and ICSD-2, (WHO 1992; APA, 2000; AASM, 2005).

\section{ICD-10 diagnosis code F51 (WHO, 1992)}

Sleep disorders not due to a substance or known physiological condition

F51.0 Nonorganic insomnia. A condition of unsatisfactory quantity and/or quality of sleep, which persists for a considerable period of time, including difficulty falling asleep, difficulty staying asleep, or early final wakening. Insomnia is a common symptom of many mental and physical disorders, and should be classified here in addition to the basic disorder only if it dominates the clinical picture. Excludes: insomnia (organic) (G47.0)

ICD-10 diagnosis code G47 (WHO, 1992)

Sleep disorders

G47.0 Disorders of initiating and maintaining sleep [insomnias]

\section{ICD-10 diagnostic criteria for non-organic insomnia}

a. A complaint of excessive daytime sleepiness or sleep attacks or prolonged transition to the fully aroused state upon awakening (sleep drunkenness) (not accounted for by an inadequate amount of sleep).

b. This sleep disturbance occurs nearly every day for at least one month or recurrently for shorter periods of time and either causes marked distress or interference with personal functioning in daily living.

c. Absence of auxiliary symptoms of narcolepsy (cataplexy, sleep paralysis, hypnagogic hallucinations) or of clinical evidence for sleep apnea (nocturnal breath cessation, typical intermittent snorting sounds, etc.). 
d. Absence of any known causative organic factor, such as a neurological or other medical condition, psychoactive substance use disorder or a medication.

\section{DSM-IV-TR diagnostic criteria for primary insomnia (APA, 2000)}

a. The predominant complaint is difficulty initiating or maintaining sleep, or nonrestorative sleep, for at least 1 month.

b. The sleep disturbance (or associated daytime fatigue) causes clinically significant distress

c. The sleep disturbance does not occur exclusively during the course of narcolepsy, breathing-related sleep disorder, circadian rhythm sleep disorder, or parasomnia.

d. The disturbance does not occur exclusively during the course of another mental disorder (e.g., major depressive disorder, generalized anxiety disorder, a delirium).

e. The disturbance is not due to the direct physiological effects of a substance.

\section{Diagnostic criteria for insomnia (ICSD-2, 2005)}

a. A complaint of difficulty initiating sleep, difficulty maintaining sleep, or waking up too early, or sleep that is chronically nonrestorative or poor in quality.

b. The above sleep difficulty occurs despite adequate opportunity and circumstances for sleep.

c. At least one of the following forms of daytime impairment related to the nighttime sleep difficulty is reported by the patient:

1. Fatigue or malaise;

2. Attention, concentration, or memory impairment;

3. Social or vocational dysfunction or poor school performance;

4. Mood disturbance or irritability;

5. Daytime sleepiness;

6. Motivation, energy, or initiative reduction;

7. Proneness for errors/accidents at work or while driving;

8. Tension, headaches, or gastrointestinal symptoms in response to sleep loss; and

9. Concerns or worries about sleep.

In conclusion, according to the diagnostic criteria listed above, we need the following symptoms to diagnose insomnia:

1. Presence of sleep disorders (difficulty falling asleep, difficulty staying asleep, or early wakening) during the better part of the night and persistent for at least one month

2. Worsened daytime functioning caused by these sleep disorders.

\section{ICD-10 classifications also divide insomnia into different forms}

ICD-10 sleep disorders

- organic insomnia

- $\quad$ nonorganic insomnia

DSM-IV diagnoses of sleep disorders

- $\quad$ Primary sleep disorders

- Dyssomnias

- Primary insomnia 
- Sleep disorders related to another mental disorder

- Insomnia related to another mental disorder

- Secondary sleep disorders due to an Axis III condition

- Insomnia type

- $\quad$ Substance-induced sleep disorders

- Insomnia type

ICSD-2 sleep disorder categories - insomnias (specific disorders)

\section{Adjustment (acute) insomnia}

The essential feature of this disorder is the presence of insomnia in association with an identifiable stressor, such as psychosocial, physical, or environmental disturbances. The sleep disturbance has a relatively short duration (days-weeks) and is expected to resolve when the stressor resolves.

\section{Psychophysiological insomnia}

The essential features of this disorder are heightened arousal and learned sleep-preventing associations. Arousal may be physiological, cognitive, or emotional, and characterized by muscle tension, "racing thoughts," or heightened awareness of the environment. Individuals typically have increased concern about sleep difficulties and their consequences, leading to a "vicious cycle" of arousal, poor sleep, and frustration.

\section{Paradoxical insomnia}

The essential feature of this disorder is a complaint of severe or nearly "total" insomnia that greatly exceeds objective evidence of sleep disturbance and is not commensurate with the reported degree of daytime deficit. Although paradoxical insomnia is best diagnosed with concurrent PSG and self-reports, it can be presumptively diagnosed on clinical grounds alone. To some extent, "misperception" of the severity of sleep disturbance may characterize all insomnia disorders.

\section{Idiopathic insomnia}

The essential feature of this disorder is a persistent complaint of insomnia with insidious onset during infancy or early childhood and no or few extended periods of sustained remission. Idiopathic insomnia is not associated with specific precipitating or perpetuating factors.

\section{Insomnia due to mental disorder}

The essential feature of this disorder is the occurrence of insomnia that occurs exclusively during the course of a mental disorder, and is judged to be caused by that disorder. The insomnia is of sufficient severity to cause distress or to require separate treatment. This diagnosis is not used to explain insomnia that has a course independent of the associated mental disorder, as is not routinely made in individuals with the "usual" severity of sleep symptoms for an associated mental disorder.

\section{Inadequate sleep hygiene}

The essential feature of this disorder is insomnia associated with voluntary sleep practices or activities that are inconsistent with good sleep quality and daytime alertness. These practices and activities typically produce increased arousal or directly interfere with sleep, 
and may include irregular sleep scheduling, use of alcohol, caffeine, or nicotine, or engaging in non-sleep behaviors in the sleep environment. Some element of poor sleep hygiene may characterize individuals with other insomnia disorders.

\section{Insomnia due to a drug or substance}

The essential feature of this disorder is sleep disruption due to use of a prescription medication, recreational drug, caffeine, alcohol, food, or environmental toxin. Insomnia may occur during periods of use/exposure, or during discontinuation. When the identified substance is stopped, and after discontinuation effects subside, the insomnia is expected to resolve or substantially improve.

\section{Insomnia due to medical condition}

The essential feature of this disorder is insomnia caused by a coexisting medical disorder or other physiological factor. Although insomnia is commonly associated with many medical conditions, this diagnosis should be used when the insomnia causes marked distress or warrants separate clinical attention. This diagnosis is not used to explain insomnia that has a course independent of the associated medical disorder, and is not routinely made in individuals with the "usual" severity of sleep symptoms for an associated medical disorder.

Insomnia not due to substance or known physiologic condition, unspecified; physiologic (organic) insomnia, unspecified

These two diagnoses are used for insomnia disorders that cannot be classified elsewhere but are suspected to be related to underlying mental disorders, psychological factors, behaviors, medical disorders, physiological states, or substance use or exposure. These diagnoses are typically used when further evaluation is required to identify specific associated conditions, or when the patient fails to meet criteria for a more specific disorder.

Judging the categories presented above from a practical and clinical point of view we have to admit that none of them is sufficient for diagnosing and treatment of insomnia. ICD-10 divides insomnia into nonorganic and organic form which is a big simplification while ICSD proposes a way too complicated categorizing which does not make it useful in everyday practice. Definitely, the most useful of all systems is the DSM-IV-TR classification system, dividing insomnia into 4 categories:

- Primary insomnia

- Insomnia related to another mental disorder

- Insomnia due to medical disorders

- Substance-induced insomnia

We estimate that this classification is the most useful and helpful in diagnosis and treatment of insomnia.

\subsection{Practical categorization of insomnia}

Because other chapters of this book encompasses a complex analysis of secondary insomnia, in the following part we are going to focus on the pure-form primary insomnia, described also as nonorganic insomnia, primary insomnia or psychophysiological insomnia in different diagnostic criteria. When diagnosing a new patient it is very important to properly assess the 
problem. We have to know if the troubles a patient declares meet criteria of insomnia. Based on carefully collected medical history about behaviors related to sleep and sleep diary analysis we often see that many patients, especially the older ones, spend 8 to 10 hours daily in bed, sleeping only 5 to 7 hours in that time. As a result, though they sleep well, their time spent in bed includes a few additional hours of WASO (Wakefulness After Sleep Onset). Such a state can hardly be classified as a real insomnia; though a patient does not fulfill their entire need for sleep, it has to be said that patient's expectations of sleeping through 8 hours in the night without interruptions are not realistic. Sleep disorder like this cannot be classified as insomnia; we can call them inadequate sleep hygiene or unrealistic expectations of sleep. Treatment of these disorders should not be done by fulfilling patient's expectations, but by making them more realistic. A second group of sleep disorders often wrongly classified as insomnia concerns mainly young people complaining about sleepiness during daytime, fatigue and troubles with waking up in the morning. But the analysis of their behaviour and sleep diary shows that usually because of work, learning or play almost every night they sleep less than other in the same age group. Such a state called sleep deprivation rather not insomnia.

After diagnosing the real insomnia, the most important part is determining how long it persists. The traditional categorizing divides insomnia into:

- Transient insomnia - a few days

- $\quad$ Acute insomnia - up to 4 weeks

- Chronic insomnia - longer than one month (NIMH, 1984).

Transient insomnia lasts for a few days to a week, acute insomnia (up to one month) and chronic insomnia (more than one month). Transient and acute insomnias are usually related to some kind of trigger (stress, noise, pain). Chronic insomnia can be related to another sickness but more often, it is caused by so - called perpetuating factors which cause insomnia to remain even when the primary causation of it is gone. We can conclude that while the short-term insomnia is usually secondary, the chronic one becomes primary.

\subsection{Insomnia diagnosis}

Because only 1 / 3 of patients reported their sleep problems to physician (Szelenberger \& Skalski, 1999, Pentor 2000), undoubtedly the first and most important task in the diagnostic process is to find patients with sleep disorders. It is therefore recommended that the questions about the quality of sleep and mood in the morning are a regular part of every medical interview, in almost every medical specialty. Patients with insomnia should go immediately to their general practitioners and begin the correct treatment.

The main diagnostic tool is the interview focused on sleep, respectively, accompanied by any further diagnostic tests for determining somatic or psychiatric causes of insomnia (Table 1).

\subsection{Development of chronic insomnia}

Modern views on etiology and pathogenesis of insomnia show correlation between various biological, medical and environmental factors in creating insomnia and causing it to persist. These factors can be divided into 3 groups - 3P (Spielman, 1986):

Predisposing factors - being prone to insomnia, biological grounds like personality, maintaining circadian rhythm, age, genetics. 


\begin{tabular}{|c|}
\hline I. Interview schedule: \\
\hline $1^{\text {st }}$ Determine the type and nature of sleep disorders: \\
\hline $2^{\text {nd }}$ Disease and associated factors: \\
\hline $\begin{array}{l}\text { - Somatic diseases and medications } \\
\text { - Psychosocial stress } \\
\text { - Mood disorders }\end{array}$ \\
\hline $3^{\text {rd }}$ Sleep before the onset of symptoms: \\
\hline $\begin{array}{l}\text { - The quality of sleep before the onset of insomnia } \\
\text { - The earlier episodes of insomnia } \\
\text { - Other sleep disorders } \\
\text { - Reaction to treatment }\end{array}$ \\
\hline $4^{\text {th }}$ Sleep hygiene: \\
\hline $\begin{array}{l}\text { - Time of lie down and getting up from bed } \\
\text { - Sleep on weekdays and holidays } \\
\text { - Variable working hours in the day and night, shift work } \\
\text { - Naps during the day } \\
\text { - Physical exercise habits and lifestyle } \\
\text { - Consumption of coffee, alcohol and other drugs }\end{array}$ \\
\hline $5^{\text {th }}$ Information from bed partner: \\
\hline $\begin{array}{l}\text { - Snoring and irregular breathing } \\
\text { - Movements during sleep } \\
\text { - Evaluation of sleep length and quality of patient } \\
\text { - Changes in mood and behavior of the patient }\end{array}$ \\
\hline II. Somatic Research, depending on the patient's complaints focused on the search: \\
\hline $1^{\text {st }}$ rheumatic \\
\hline $2^{\text {nd }}$ respiratory and ENT \\
\hline $3^{\text {rd }}$ cardiovascular \\
\hline $4^{\text {th }}$ renal \\
\hline $5^{\text {th }}$ neurological \\
\hline $6^{\text {th }}$ cancer \\
\hline 7th gastrological \\
\hline III. Psychiatric and psychological assessment: \\
\hline $1^{\text {st }}$ on the basis of conversation \\
\hline - Behavior changes \\
\hline - Mood changes \\
\hline - Anxiety \\
\hline - Psychosocial stress situations \\
\hline - Excessive preoccupation with his dream \\
\hline 2nd based on scales, e.g. \\
\hline $\begin{array}{l}\text { - Beck Depression Scale (self) } \\
\text { - Hamilton Depression Rating Scale } \\
\text { - Hamilton anxiety scale } \\
\text { - Dementia assessment scale (Mini Mental State) } \\
\text { - MMPI personality assessment scale }\end{array}$ \\
\hline
\end{tabular}




\begin{tabular}{|l|}
\hline 3rd eventual referral to a psychologist or psychiatrist \\
\hline IV. Sleep monitoring studies: \\
\hline $1^{\text {st }}$ polysomnographic study \\
\hline $2^{\text {nd }}$ actigraphic registration \\
\hline $\begin{array}{l}3^{\text {rd }} \text { study MSLT (Multiple Sleep Latency Test allows an objective assessment of excessive } \\
\text { sleepiness) }\end{array}$ \\
\hline
\end{tabular}

Table 1. Examination scheme of patients with sleep disorders

Precipitating (Triggers) factors causing sleep interruptions directly - environmental, adaptive, medical

Perpetuating factors - drugs abuse, improper sleep hygiene, exaggerated expectations of sleep, the fear of insomnia - often create a vicious circle of insomnia.

There is more and more evidence that people with insomnia are constantly in the state of socalled hyperarousal. Many of them are less sleepy during daytime, which can be measured by studying duration of their naps. These people also have significantly increased metabolism level during the whole 24 hours. Consequently, assumptions have been made that in patients with chronic insomnia the main and most common problem is the excessive arousal responsible both for poor functioning during daytime and problems with sleep at night. People with insomnia have increased ACTH level and raised cortisol secretion and lowered inhibitory neurotransmitter GABA level. (Bonnet \& Arand, 1997; Perlis et al. 1998; Vgontzas et al. 1998; Winkelman et al., 2008)

Knowledge of the mechanisms listed above is extremely important for successful treatment requiring focus on various aspects of insomnia. Contemporary rules say that the treatment should be commenced with the occurrence of the very first symptoms of insomnia to quickly eliminate the causes and avoid perpetuating mechanisms.

\section{Treatment of insomnia}

When to start with treatment of insomnia, how and by whom should it be treated?

In any case, if sleep problems persist for longer than 2-3 weeks and begin to negatively impact on functioning during the day, be sure to seek medical advice.

In the case of short-term insomnia, especially in those predisposed to insomnia, it is necessary to take treatment as soon as possible. It is usually sufficient administration of temporary hypnotic drug. The patient places the sleeping pill, near the bed and reaches for it when can not sleep. This treatment protects the patient against the occurrence of factors perpetuate insomnia and prevents against the development of chronic insomnia.

In chronic insomnia administration of hypnotics is neither effective nor consistent with the principles of administration of hypnotics (no longer than 2-4 weeks). In addition, perpetuates and worsening course of insomnia and increases the risk of dependence on hypnotics. The primary method of treatment for chronic insomnia is behavioral therapy. 


\subsection{Non-pharmacological treatment of insomnia}

There are numerous methods of non-pharmacological treatment of insomnia. They include:

- $\quad$ - information on the sleep hygiene principles,

- $\quad$ - stimulus control,

- - sleep restriction,

- $\quad$ - relaxation techniques,

- - feedback,

- $\quad$ - cognitive therapy,

- - "chronotherapy",

- $\quad$ - phytotherapy (Morin, 1999; Yang, 2005; Schutte-Rodin, 2008).

\subsubsection{Behavioral techniques}

\subsubsection{Sleep hygiene education}

The sleep hygiene principles include: refraining from naps during the day; getting to sleep and getting up at the same time; restraining or giving up consumption of caffeine, alcohol and nicotine; avoiding physical activities shortly before moving to bed, staying away of any emotional arousal before bedtime, ensuring quiet environment and comfortable temperature in a bedroom, removing clocks from a bedroom (Hauri \& Fisher, 1986).

\subsubsection{Sleep restriction}

A sleep restriction means for the patient being in bed no longer than usually sleeps at night, according to his subjective assessment (for example, by sleep diary). As the sleep's length is usually underestimated, the patient will partially deprive his sleep, reducing at the same time the number of awakenings the following night (Spielmann et al. 1987).

\subsubsection{Stimulus control therapy}

Stimulus control technique aims to restrict the bedroom and the bed for a sleep only. Reading, eating and watching television in bed is prohibited. The patient should go to bed only when feeling sleepy. If a sleep does not come within the next ten minutes, he has to get up, go to another room and return only when feeling sleepy. An alarm clock should be set always at the same time, regardless of a sleep's length. The patient also has to refrain from naps during the day (Bootzin et al. 1991).

\subsubsection{Cognitive therapy}

Insomnia-related concerns increase insomnia, causing excitation and further exacerbate sleep problems. It has been proven that the erroneous beliefs and attitudes toward sleep are associated with symptoms of insomnia. Changing negative thoughts can reduce concerns about the lack of sleep and break the vicious circle leading to excitation and insomnia.

Common incorrect beliefs about sleep can be classified into five categories:

1. misunderstanding of insomnia's causes,

2. seeking incorrect or exaggerated insomnia consequences

3. unrealistic expectations of sleep, 
4. limited perception of control over sleep

5. belief that sleep could be predictable.

Incorrect beliefs about sleep can be corrected by educating patients about the principles of the sleep hygiene. The aim of the cognitive therapy is the recognition by the patient that he can cope with the problem of insomnia. (Morin et al. 1999; 2002).

For several years, in Warsaw Sleep Disorders Clinic we regularly conduct CBT group therapy (six sessions, every week, number of patients 6-10). Our findings confirmed the high efficacy of the CBT therapy. CBT-I produced sustained self-reported improvement in nocturnal sleep and daytime functioning (Fornal-Pawłowska et al., 2010). After 3 months, insomniacs did not differ from good sleepers in sleep quality and social functioning ratings (Fig. 1 and 2).

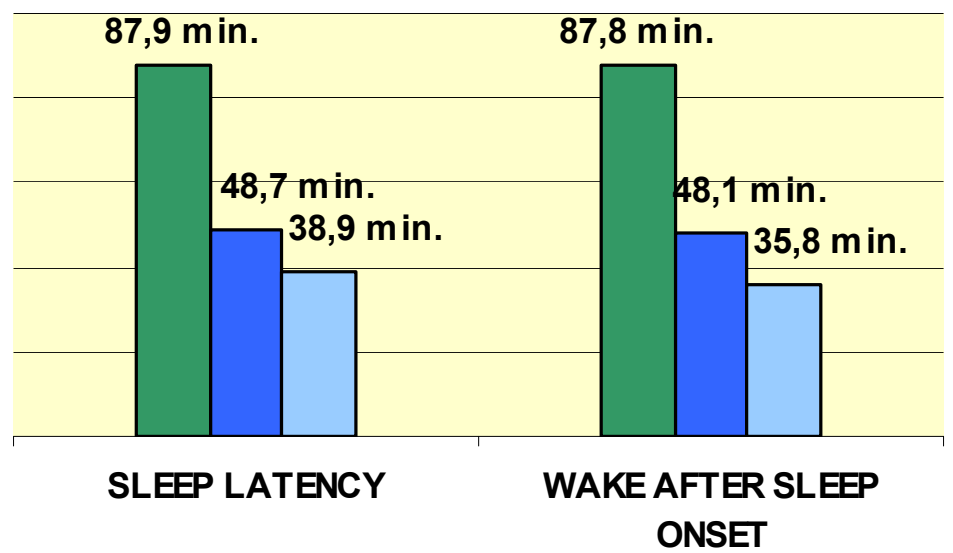

Fig. 1. Changes in sleep parameters: sleep latency and WASO, at baseline, post-treatment and the 3-month follow-up

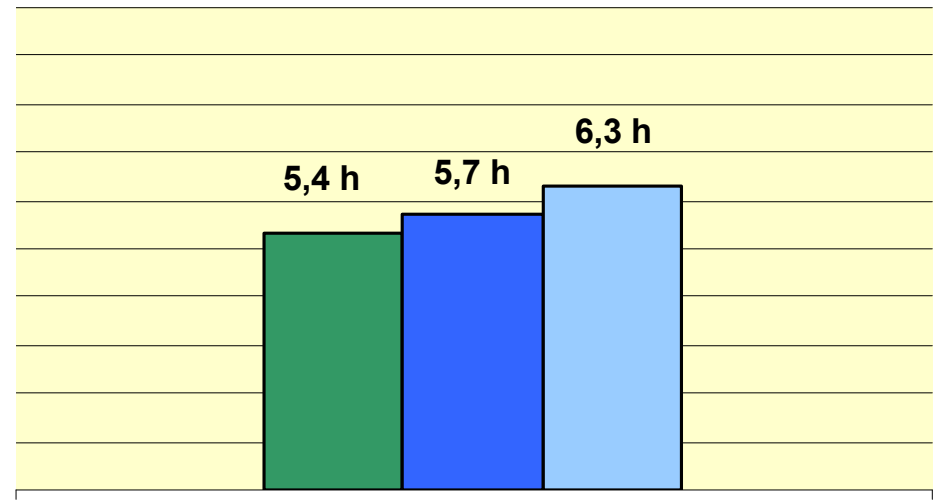

TOTAL SLEEP TIME

Fig. 2. Changes in total sleep time at baseline, post-treatment and the 3-month follow-up 


\subsubsection{Summary of non-pharmacologic strategies}

For the past 10 years in our sleep disorders clinic in Warsaw CBT of insomnia has become a routine method of treatment for chronic insomnia. It consists of 6 sessions which take place once a week, in groups consisting of 6-10 people. In the following sessions, patients are educated about the physiology of sleep and sleep disorders. Then learn the next technique: education about sleep hygiene, sleep restriction, stimulus control, relaxation exercises, and finally cognitive therapy oriented at dysfunctional thoughts related to insomnia. In parallel, patients receive information about rational pharmacotherapy of insomnia, which is only occasional use of hypnotics (2-3 times a week) and possibly the use of low doses of antidepressant drugs or herbal medicines. The results so far are very promising (shown in the Figures above) and indicate that the CBT treatment of insomnia is currently the most effective treatment for chronic insomnia.

\subsection{Pharmacological treatment of insomnia}

Drug treatment is indicated for patients as short-term relief of symptoms of insomnia but is insufficient for long-term management of chronic insomnia. In combination with cognitivebehavioral therapy, it gives the best results in improving the quality of sleep. (Riemann\&Perlis, 2009; Saddichha, 2010).

\subsubsection{Benzodiazepine Receptor Agonists (BZD or newer BzRAs)}

The most widely used method for insomnia is to administer benzodiazepine receptor agonists (Yang, 2005; Schutte-Rodin, 2008). This group includes all the traditional benzodiazepines (BZD) and hypnotics new generation (benzodiazepine receptor agonists BzRAs) - zolpidem, zopiclone and zaleplon.

\subsubsection{Benzodiazepines}

The selection of a specific benzodiazepine agonist should be performed in accordance with the knowledge of its pharmacokinetics. When changing the medication, be sure to equivalent doses of different preparations.

Objective results of treatment with hypnotics are small: latency is shortened by 15 minutes and total sleep time increased by about 30 minutes. Benzodiazepines do not improve sleep quality. Rapidly lose their hypnotic effect, sometimes after a few days. Dependence develops after regular ingestion of several weeks. Prevention of tolerance and addiction is the administration of hypnotics no more than 2-3 times a week and the lowest dose, repeat the drug at intervals of less than four times the value of its half-life leading to accumulation (Walsh et al. 2000; Hajak et al. 2002; Perlis, 2004).

\subsubsection{Non-benzodiazepine hypnotics}

In comparison with traditional BZD new generation hypnotic drugs appear to be a major step forward. Zolpidem and zaleplon are selective benzodiazepines receptor agonist. Because of their selective action on the omega-1 receptor, subclass of BZD receptors they do not affect cognition, memory and motor function. Zolpidem, zopiclone, and zaleplon rapidly absorbed and have a short biological half-life. This is important because residual symptoms the next day, that is, impairment of psychomotor skills and memory, depend on 
the biological half-life time. It is believed that the new benzodiazepine receptor agonists hypnotics give less risk of tolerance and dependence.

Need to be aware that in a patient with insomnia, hypnotic drug administration is only supportive care, relieving symptom of disease rather than treating disease.

Of course, the effects of hypnotics may be helpful in the general treatment of insomnia, when once again "we teach" patients sleep. But leaving the patient without the comprehensive support reduces the effectiveness of treatment, and very easily lead to addiction

\subsubsection{Summarize the role of hypnotics in insomnia}

In the short-term insomnia:

- $\quad$ Recognize as soon as possible insomnia and give patients a new generation of hypnotics (zolpidem, zopiclone, zaleplon), which may prevent in a patient developing in perpetuating factors

- The best method is to put the sleeping pills near the bed and reaching for it, when the patient is waiting too long to fall asleep after laying to bed, or in the event of the night awakenings

- Such way taking of sleeping pills will allow most patients with insomnia to avoid shortterm transition in chronic insomnia, and at the same time protect them from dependence on hypnotics.

- The experiences of our everyday practice show that mere possession of an effective sleeping pills near the bed allows the patient to sleep better.

In the chronic insomnia:

- $\quad$ Do not chronic use of hypnotics (benzodiazepine receptor agonists), with daily use and must not be taken for more than 2 weeks.

- They can be take longer, but only if they are used temporarily "as needed" which is 2 to 3 times a week (or up to 10 times a month).

- $\quad$ Sleeping pills can be used if the patient also use behavioral techniques.

- Almost all patients after therapy, CBT, occasionally use sleeping pills, only a few times a month. Even if earlier abused benzodiazepines.

\subsubsection{Sedative low dose antidepressant (AD)}

In recent years, increasingly in the supportive treatment of insomnia is proposed to use the drugs from other groups deserve special attention and antidepressants, natural remedies, available without prescription (Thase, 1999; James \& Mendelson 2004; Krystal et al. 2010).

In clinical practice, in case of necessity of prolonged treatment of insomnia alternative to the sleeping pills are antidepressants with sedative-hypnotic properties. The most commonly used drugs of such a profile are Trazodone, Mianserin, Mirtazapine, Doxepin. It has been proven that improves sleep in people suffering from insomnia and increases the amount of SWS. Some tricyclic antidepressants (TCAs) are also strong action sleeping pills. However, due to non-selective effect, causing more side effects. 
There is no fixed standard dosage in the treatment of insomnia, usually are used in low doses in comparison to those used in depression. (James \& Mendelson 2004; Krystal et al. 2010).

In everyday practice, Warsaw Sleep Disorders Clinic doses fully sufficient as a "hypnotic", are:

- $\quad$ mianserin 5 to $15 \mathrm{mg}$

- $\quad$ trazodone 25 do $100 \mathrm{mg}$

- $\quad$ mirtazapine 7,5 do $15 \mathrm{mg}$

The above mentioned dose are the smallest as possible to achieve (the tablets can not be divided any more), it is possible that even lower doses might be effective. Such small doses are usually very well tolerated and, in addition antidepressants do not give a risk of addiction. The most common side effect of what we find in our patients the symptoms of restless leg syndrome (RLS), usually after mianserin, less frequently after trazodone.

But even with such a small and safe doses should be avoided their chronic use, so that the patients do not used to falling asleep on the pills. Usually after a normalization of sleep and sleep hygiene correction also we recommend discontinuing medication.

\subsubsection{Over-the-counter agents}

In the insomnia is also used medicines available without prescription, such as melatonin, antihistamines and herbal medicines. These drugs are increasingly used (Montserrat Sanchez-Ortuno et al., 2009), but still is little systematic studies. From the few the available data it is estimated that natural remedies used from 4 to $18 \%$ of all people and from 30 to over $70 \%$ of those complaining of insomnia (Montserrat Sánchez-Ortuño et al., 2009; Sarris \& Byrne, 2010; Salter \& Brownie, 2010). So far performed too small amount of normal, placebocontrolled studies to evaluate the effectiveness of drugs used without a prescription for insomnia. Published in the last year review of all available studies of natural drugs and methods used in insomnia indicate an advantage of preparations containing valerian and hops in the improvement of various parameters of sleep (Montserrat Sánchez-Ortuño et al., 2009).

\subsubsection{The risk of dependence}

When discussing pharmacological treatment of insomnia can not ignore the problem dependence benzodiazepines. Experience our Sleep Disorders Clinic indicate that a large proportion of patients with chronic insomnia are more or less dependent on benzodiazepines. In a large part of patients, the existing dependence seems to be the primary cause of insomnia. In this case, the first stage of treatment is the gradual withdrawal of benzodiazepines and to manage the withdrawal symptoms. In the treatment of benzodiazepines dependence in patients with insomnia CBT therapy was very effective (Morin et al., 2004), also routinely used in our Warsaw Sleep Disorders Clinic.

\section{Summary}

The current rules establish that the treatment of insomnia should start right from the beginning of its occurrence, to avoid appearance of perpetuating factors - chronic insomnia development. 
In the case of the diagnosis of transient or short-term insomnia, a basic method of treatment is usually administrating the right hypnotics and information on the sleep hygiene.

In chronic insomnia, a basic treatment is cognitive-behavioral therapy (CBT), which can help pharmacologically by regular use of "sedative and hypnotic" antidepressant medication in the evening only "as needed" taking hypnotics drugs (no more than 2-3 times a week).

\section{References}

American Academy of Sleep Medicine. (2005). ICSD - International Classification of Sleep Disorders, 2nd ed.: Diagnostic and coding manual. Westchester, Illinois: American Academy of Sleep Medicine.

American Psychiatric Association. (2000). Diagnostic and Statistical Manual of Mental Disorders, Fourth Edition, Text Revision. Washington, DC: The American Psychiatric Association; 2000.

Anderson C \& Horne JA. (2008) Do we really want more sleep? A population-based study evaluating the strength of desire for more sleep. Sleep Medicine, 9, 184-187. ISSN: 1389-9457

Bixler E. (2009). Sleep and society: An epidemiological perspective. Sleep Medicine, 10, s3-s6. ISSN: 1389-9457

Bonnet MH, Arand DL. (1997). Hyperarousal and insomnia. Sleep Med Rev., 2:97-108. ISSN: 1087-0792

Bootzin R.R., Epstain D., Wood J.M. (1991). Stimulus control instructions. In Case Studies in Insomnia. Hauri P. (ed.) Plenum Medical Book Co., New York. 19-28.

Borbely AA. (1982). A two process model of sleep regulation. Hum Neurobiol. 1, 195-204. ISSN: 0721-9075

Fornal-Pawlowska M., Skalski M., Szelenberger W. (2010). Cognitive behavioural therapy for insomnia. Journal of Sleep Research 2010; 19 (Suppl. 2): P479. 158

Hajak G, Cluydts R, Declerck A, Estivill SE, Middleton A, Sonka K, Unden M. (2002). Continuous versus non-nightly use of zolpidem in chronic insomnia: results of a large-scale, double-blind, randomized, outpatient study.Int Clin Psychopharmacol.(Jan) 17:9-17.

Hauri P., Fisher J. (1986). Persistent psychophysiologic (learned) insomnia. Sleep. 9: 38-53.

James SP, Mendelson WB. (2004). The use of trazodone as a hypnotic: a critical review. J Clin Psychiatry. 65:752-755. ISSN: 1555-2101

Kryger MH, Roth T \& Dement C. (2011). Principles and practice of sleep medicine. $5^{\text {th }}$ Edition. Elsevier Saunders Company, ISBN 978-1-4160-6645-3, Philadelphia.

Krystal AD; Durrence HH; Scharf M; Jochelson P; Rogowski R; Ludington E; Roth T. (2010). Efficacy and safety of doxepin $1 \mathrm{mg}$ and $3 \mathrm{mg}$ in a 12-week sleep laboratory and outpatient trial of elderly subjects with chronic primary insomnia. Sleep, 33(11). 1553-1561.

Montserrat Sánchez-Ortuño M ; Bélanger L; Ivers H; LeBlanc M; Morin CM. (2009). The use of natural products for sleep. A common practice? Sleep Medicine. 10. 982-987

Morin CM, Hauri PJ, Espie CA, Spielman AJ, Buysse DJ, Bootzin RR. (1999). Nonpharmacologic treatment of chronic insomnia. An American Academy of Sleep Medicine review. Sleep, 22:1-23. 
Morin CM. (2002). Contributions of Cognitive-Behavioral Approaches to the Clinical Management of insomnia. J Clin Psychiatry, 4, suppl 1: 21-26

Morin CM, Bastien C, Guay B, Radouco-Thomas M, Leblanc J, Vallières A. (2004). Randomized Clinical Trial of Supervised Tapering and Cognitive Behavior Therapy to Facilitate Benzodiazepine Discontinuation in Older Adults With Chronic Insomnia. Am J Psychiatry; 161:332-342

National Institute of Mental Health. (1984). Drugs and Insomnia: The Use of Medications to Promote Sleep. JAMA. 251(18). 2410-2414. ISSN: 0098-7484

Ohayan MM, Caulet M, Priest RG, Guilleminault C. (1997). DSM-IV and ICSD-90 insomnia symptoms and sleep dissatisfaction. Br J Psychiatry, 171:382-388.

Pan-European Consumer Omnibus Study. (2000). Pentor.

Perlis ML, Giles DE, Mendelson WB, Bootzin RR, Wyatt JK. (1997). Psychophysiological insomnia: the behavioral model and a neurocognitive perspective. J Sleep Res 1997, 6:179-188. ISSN: 1365-2869

Perlis ML. (2004). Long-term, non-nightly administration of zolpidem in the treatment of patients with primary insomnia. J Clin Psychiatry.65:1128-37.

Riemann D, Perlis ML. (2009). The treatments of chronic insomnia: A review of benzodiazepine receptor agonists and psychological and behavioral therapies. Sleep Med Rev. 13: 205-14.

Saddichha S. (2010). Diagnosis and treatment of chronic insomnia. Ann Indian Acad Neurol. 21, 13: 94-102

Salter S; Brownie S. (2010). Treating primary insomnia - the efficacy of valerian and hops. Australia in Family Physician, 39, 6, june, 433-437

Saper CB, Chou TC, Scammell TE: (2001). The sleep switch: hypothalamic control of sleep and wakefulness. Trends in Neurosciences, 24, 12. 726-731. ISSN: 0166-2236

Saper CB, Lu J, Chou TC, Gooley J. (2005). The hypothalamic integrator for circadian rhythms. Trends in Neurosciences. 28, 3. 152-157. ISSN: 0166-2236

Sarris J; Byrne G J. (2010). A systematic review of insomnia and complementary medicine. Sleep Medicine Reviews. Apr;15(2):99-106. ISSN: 1087-0792

Schutte-Rodin S; Broch L; Buysse D; Dorsey C; Sateia M. (2008). Clinical guideline for the evaluation and management of chronic insomnia in adults. J Clin Sleep Med; 4(5):487-504.

Spielman AJ. (1986). Assessment of insomnia. Clin Psychol Rev. 6:11-25. ISSN: 0272-7358

Spielman A.J., Saskin P., Thorpy M.J. (1987). Treatment of chronic insomnia by restriction of time in bed. Sleep. 10: 45-56.

Szelenberger W., Skalski M. (1999). Epidemiologia zaburzeń snu w Polsce. Doniesienie wstępne. W: Nowicki Z., Szelenberger W. red. Zaburzenia snu. Diagnostyka i leczenie, wybrane zagadnienia. Biblioteka Psychiatrii Polskiej, Kraków; 57-63.

Szelenberger W. (2006). Standardy leczenia bezsenności Polskiego Towarzystwa Badań nad Snem. Sen, 2006, 6, supl. A:1-10.

Szelenberger w (ed.). (2007). Bezsenność. Via Medica, Gdańsk, 2007. ISBN 978-83-600072-61-5

Thase ME. (1999). Antidepressant treatment of the depressed patient with insomnia. J Clin Psychiatry. 60 (Suppl 17). 28-31. ISSN: 1555-2101

Walsh J, Roth T, Randazzo A, Erman M, Jamieson A, Scharf M, Schweitzer PK, Ware JC. (2000). Eight weeks of non-nightly use of zolpidem for primary insomnia. Sleep. 28:1087-96. 
Winkelman JW, Buxton OM, Jensen JE, Benson KL, O'Connor SP, Wang W, Renshaw PF. (2008). Reduced Brain GABA in Primary Insomnia: Preliminary Data from 4T Proton Magnetic Resonance Spectroscopy (1H-MRS). Sleep, 31, 11:

World Health Organization (WHO). (1992). The ICD-10 classification of mental and behavioral disorders: Clinical descriptions and diagnostic guidelines. Geneva: world Health Organization.

Vgontzas AN, Tsigos C, Bixler EO, Stratakis CA, Zachman K, Kales A, Vela-Bueno A, Chrousos GP. (1998). Chronic insomnia and activity of the stress system: a preliminary study. J Psychosom Res, 45:21-31.

Yang CM, Spielman AJ, Huang, YS. (2005). Insomnia. Current Treatment Options in Neurology, 7:373-386 


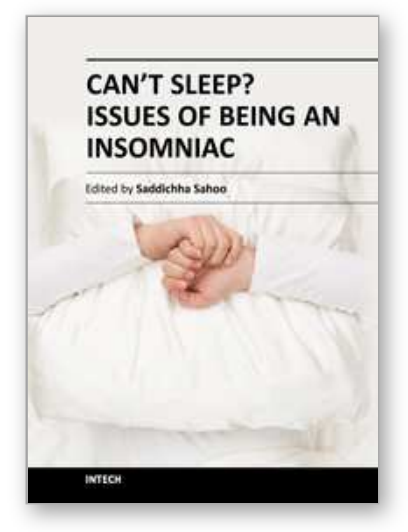

\author{
Can't Sleep? Issues of Being an Insomniac \\ Edited by Dr. Saddichha Sahoo
}

ISBN 978-953-51-0261-8

Hard cover, 110 pages

Publisher InTech

Published online 14, March, 2012

Published in print edition March, 2012

The word insomnia originates from the Latin "in" (no) and "somnus" (sleep). It is a disorder characterized by an inability to sleep or a complete lack of sleep. Various studies have noted insomnia to be quite a common condition, with symptoms present in about $33-50 \%$ of the adult population. This book provides a comprehensive state of the art review on the diagnosis and management of the current knowledge of insomnia and is divided into several sections, each detailing different issues related to this problem, including epidemiology, diagnosis, management, quality of life and psychopharmacology. In order to present a balanced medical view, this book was edited by a clinical psychiatrist.

\title{
How to reference
}

In order to correctly reference this scholarly work, feel free to copy and paste the following:

Michał Skalski (2012). The Diagnosis and Treatment of Insomnia, Can't Sleep? Issues of Being an Insomniac, Dr. Saddichha Sahoo (Ed.), ISBN: 978-953-51-0261-8, InTech, Available from:

http://www.intechopen.com/books/can-t-sleep-issues-of-being-an-insomniac/the-diagnosis-and-treatment-ofinsomnia

\section{INTECH}

open science | open minds

\section{InTech Europe}

University Campus STeP Ri

Slavka Krautzeka 83/A

51000 Rijeka, Croatia

Phone: +385 (51) 770447

Fax: +385 (51) 686166

www.intechopen.com

\section{InTech China}

Unit 405, Office Block, Hotel Equatorial Shanghai

No.65, Yan An Road (West), Shanghai, 200040, China

中国上海市延安西路65号上海国际贵都大饭店办公楼 405 单元

Phone: +86-21-62489820

Fax: $+86-21-62489821$ 
(C) 2012 The Author(s). Licensee IntechOpen. This is an open access article distributed under the terms of the Creative Commons Attribution 3.0 License, which permits unrestricted use, distribution, and reproduction in any medium, provided the original work is properly cited. 